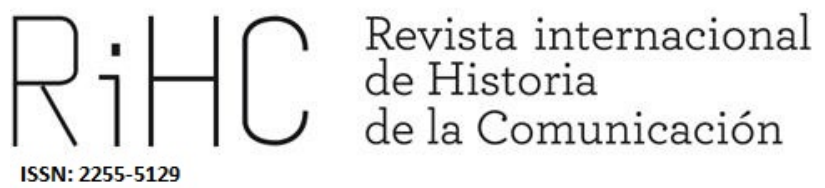

\title{
EL EMPODERAMIENTO FEMENINO EN LAS REVISTAS DE MODA. ¿REALIDAD $O$ ASPIRACIÓN?
}

\section{Female empowerment in the fashion magazines. Reality or aspiration?}

DOI: http://dx.doi.org/10.12795/RiHC.2018.i10.07

Recibido: 28/03/2018

Aceptado: $24 / 05 / 2018$

Publicado: $25 / 06 / 2018$

Sergio Luque Ortiz (D) https://orcid.org/0000-0002-4302-9503

Universidad Europea Miguel de Cervantes, sluque@uemc.es

Concha Pérez Curiel (iD) https://orcid.org/0000-0002-1888-0451

Universidad de Sevilla, cperez1@us.es

Resumen: Las revistas especializadas en moda nacen como instrumentos de difusión de contenidos especialmente dirigidos a las mujeres. Desde el desarrollo de la prensa femenina hasta la actualidad, las mujeres han ocupado cargos en la edición y dirección de los medios de comunicación consagrándose un liderazgo continuado. Sin embargo, la presencia de la mujer en la dirección de medios concretos no ha sido suficiente para 
incluir una transformación respecto a los contenidos temáticos más habituales (amor, familia, moda y belleza).

En esta investigación se analizan tres publicaciones (Telva, Vogue y Elle) dirigidas por mujeres. La elección de estas publicaciones responde a criterios contrastados como son la permanencia en el tiempo (Telva es la decana del periodismo femenino en España) y edición de ejemplares (según datos del Estudio General de Medios). El análisis de contenido de las publicaciones determina en qué medida las unidades temáticas en torno a los medios de comunicación para mujeres presentan pocas innovaciones contribuyendo a generar patrones de conducta estereotipados.

Palabras clave: Moda, mujer, revistas especializadas, análisis de contenido.

Abstract: Fashion magazines were born like instruments for disseminating content especially aimed at women. From the development of the women's press to the present, women have held positions in the editing and direction of the media, establishing a continued leadership. However, the presence of women in the direction of specific media has not been enough to include a transformation with respect to the most common thematic contents (fashion, family, beauty and affectivity).

This research analyzes three fashion magazines (Telva, Vogue and Elle) directed by women. The choice of these publications responds to contrasted criteria such as the permanence in time (Telva is the dean of female journalism in Spain) and edition of copies (according to the General Media Study). The content analysis of the publications determines to what extent the thematic units around the media for women present few innovations contributing to generate stereotyped patterns of behavior.

Keywords: Fashion, woman, specialized magazines, content analysis.

\section{Introducción}

La segmentación del discurso comunicativo por sexos forma parte de la historia del periodismo. Desde el nacimiento y posterior desarrollo de los principales periódicos y revistas de información general, la división de contenidos para satisfacer las demandas informativas de un género y otro han sido continúas. Autores como Timoteo (1997) consideran que el origen de esta práctica está en la transmisión oral de los saberes en las sociedades que traspasaban los conocimientos de generación en generación. En la Edad Media y en la Edad Moderna, las mujeres eran las encargadas de enseñar las tradiciones y las buenas costumbres a los diferentes miembros de la familia.

La sectorización por géneros es por lo tanto una consecuencia directa de la división de mensajes informativos emitidos a lo largo de la historia, aunque será durante la Revolución Industrial cuando la mujer consolide su relevancia social al ámbito doméstico siendo elementos indispensables que garantizan la unidad familiar. A partir de la industrialización, las mujeres pasaron a un segundo plano dándose una progresiva masculinización no solo laboral sino también social. Como respuesta, surgieron diferentes publicaciones dirigidas a las mujeres. 
Hay registros de un tipo de prensa exclusivamente de mujeres desde comienzos del siglo XVIII con la publicación francesa Gazette de France (1631) o la inglesa Lady's Mercury (1693). Por otra parte, "de acuerdo a la visión aportada por Schroeder Buitoni (1981), la revista Lady's Mercury ya contenía uno de las secciones más existosas de toda: el consultorio sentimental y amoroso. En el siglo XVIII nacieron diferentes publicaciones hechas por mujeres pero dirigidas por hombres. Francia se convirtió en el foco mundial del periodismo femenino siendo la publicación Le Journal des Dames (1759-1778) una de las más notables del momento. Paralelamente a esta cabecera existieron otros periódicos que ofrecían consejos diversos a las lectoras sobre temáticas como decoración, cocina, recetas o limpieza doméstica" (Luque, 2017, 377).

Además de Francia, el resto de países de Europa también contaban con publicaciones para mujeres. En Alemania, la primera revista fue Akademie der Grazien (1774-1780) con un contenido principalmente literario. En Italia, los primeros medios de comunicación femeninos fueron Toilette (1770), Biblioteca Galante (1775) y Giornale della Donne (1781). Fuera de Europa, Estados Unidos siempre ha destacado por la producción periodística en general y particularmente en la creación de revistas para mujeres. Un ejemplo concreto fue Ladies Magazine (1828).

De igual forma, "Francia, Alemania, España y Reino Unido contaron con las primeras publicaciones de este tipo. En pleno siglo XIX, el perfil de la prensa para mujeres vivió una ligera evolución. Nacieron nuevas publicaciones orientadas a reforzar las ideas revolucionarias de emancipación, libertad y autonomía que pocas mujeres podían atreverse a experimentar. En esta fase de cambios y transiciones entre un mensaje y otro, Roig (1977) señala la importancia de la escritoria italiana Elisabetta Caminer, la primera mujer directora de una publicación periodística especializada en información política: L'Europa Letteraria, además de fundadora del primer periódico abiertamente feminista del país transalpino: Eva Redenta." (Luque, 2017, 379).

El periodismo femenino ya no tenía como prioridad llegar a la élite sino cederle protagonismo informativo a las mujeres que defendían el acceso a la educación, al voto y, posteriormente, al mercado laboral. Publicaciones como La Femme Libre (18321834) o Journal des Femmes (1832-1837) representaron la transformación periodística a la que se hace referencia. Aunque los medios de comunicación de corte feminista permanecieron activos durante décadas, en el siglo XX aparecieron otras publicaciones dirigidas a las mujeres que habían abandonado el medio rural para instalarse en la ciudad adquiriendo un nivel de ingresos más alto.

El siglo XX representó otro cambio en la prensa femenina. Las mujeres se habían convertido en consumidoras propias, al margen de los bienes que comprasen para la familia. Conscientes de esta realidad, las revistas especializadas comenzaron a introducir mensajes que apelaban al consumo de productos cosméticos para lucir en perfecto estado durante más tiempo. 
Para Lipovetsky (2000), desde las primeras décadas del siglo XX hasta la actualidad la prensa femenina exalta el uso y consumo de productos cosméticos junto al de prendas de moda, de forma que la belleza pasa a ser descrita como una conquista personal del criterio de cada mujer. Resulta lógico entender como la existencia de un concepto considerado como prensa femenina demuestra que todo el ámbito femenino existe como una supuesta oposición a lo masculino, mientras que la asignación de funciones masculinas son consideradas como elementos universales y referenciales del poder, el estatus y la realización profesional.

En ese sentido, las revistas femeninas funcionan como reductos editoriales en los que mostrar la plena integración de la mujer en el ámbito laboral (aunque esa integración sea relativa y discutida sobre todo en términos de representación de las mujeres en puestos directivos de multinacionales), social (sin dar cabida a las historias protagonizadas por mujeres anónimas que son víctimas del repudio social al no estar conformes con la maternidad) y económica.

Las páginas de estas revistas dedican un espacio destacado a los casos de éxito femeninos al mostrar a mujeres de negocios que sirven como referentes para las lectoras. En este sentido cabe recordar que "las revistas ilustradas femeninas cultivan y difunden un modelo modernista, construido sobre la base de un estereotipo de mujer de estrato socioeconómico acomodado, en una sociedad industrializada de la esfera capitalista"(Mattelart, 1982, 35).

Las revistas femeninas son manuales de conducta que incluyen guías imprescindibles de conocimientos y comportamientos que toda mujer debe conocer para sentir la integración social a la que aspira. De esta forma, la mujer sigue aceptando su rol asignado bajo una leve pátina de pretendida modernidad. La prensa ha reforzado el papel atribuido por la sociedad a la mujer con la intención de garantizar así la sumisión de ésta al orden establecido enalteciendo el aspecto estético y físico mediante artículos de belleza y prendas de moda como dos valores indisolubles a toda mujer. La influencia que ejercen los medios de comunicación en cuanto a la formación de las actitudes generales refleja situaciones cotidianas de la sociedad teniendo sus raíces en una profunda desigualdad política, económica y cultural que ha forzado a mantener en una posición inferior a las mujeres. 


\section{Características de las revistas femeninas. Unidades temáticas y contenidos}

Determinar el liderazgo de las mujeres en las dirección de las revistas femeninas no sería posible sin adquirir inicialmente una aproximación general al concepto de revista, tanto como medio de comunciación como soporte para divulgar información. Teóricos y expertos han aportado diferentes interpretaciones sobre el concepto. Sin embargo, Cabello (1999) va más allá al considerar que las revistas femeninas deben cumplir una serie de características concretas resumidas en el siguiente cuadro.

\begin{tabular}{|l|l|}
\hline \multicolumn{2}{|l|}{ Características de las revistas femeninas } \\
\hline Rasgo identificatorio & Descripción \\
\hline Periodicidad & $\begin{array}{l}\text { Es necesario que la publicación tenga una periodicidad } \\
\text { determinada, bien sea semanal, quincenal o mensual. Las } \\
\text { revistas analizadas tienen una periodicidad mensual. }\end{array}$ \\
\hline Idea empresarial & $\begin{array}{l}\text { En su origen hay una idea emprendedora con la finalidad } \\
\text { última de atender a las necesidades individuales. }\end{array}$ \\
\hline $\begin{array}{l}\text { Captación de las } \\
\text { necesidades }\end{array}$ & $\begin{array}{l}\text { Una revista tienen mayor calidad cuanto mejor descubra } \\
\text { las necesidades reales que presenta el lectorado al que se } \\
\text { dirige sin crear demandas artificiales de información. }\end{array}$ \\
\hline $\begin{array}{l}\text { Valoración de las } \\
\text { necesidades }\end{array}$ & $\begin{array}{l}\text { Una revista debe poseer la capacidad para comtemplar la } \\
\text { realidad más detenidamente y ofrecer así más detalles } \\
\text { sobre los hechos. }\end{array}$ \\
\hline $\begin{array}{l}\text { Satisfacción de las } \\
\text { necesidades }\end{array}$ & $\begin{array}{l}\text { Una revista debe presentar diferentes posibilidades de } \\
\text { ofrecer varios soportes y así crear un clima de prestigio } \\
\text { comuncativo. }\end{array}$ \\
\hline
\end{tabular}

Fuente: Gallego (1999). Elaboración: Tesis doctoral Sergio Luque Ortiz (2017)

Otros autores como Bonvoisin y Maignien (1986) determinan que las revistas femeninas son publicaciones escritas y dirigidas por mujeres y que tratan contenidos tradicionalmente femeninos como son la cocina, los trabajos domésticos o la decoración. Pero esta afirmación está sujeta a ciertos matices. Revistas femeninas como Vogue, Glamour y House and Garden fueron creadas por Arthur Baldwin Turnure, un editor americano que fundó el conglomerado mediático Condé Nast, uno de los más rentables de la industria mediática y uno de los grupos de medios de comunicación especializados en publicaciones de moda más importantes del mundo. 
Por su parte, Perinat y Marrades (1980) sostienen que las revistas femeninas son aquellas publicaciones que ya sea por el título o el subtítulo (por declararlo de tal forma a sus redactoras o por la temática) tienen como destinatario principal a las mujeres. De igual forma, "tradicionalmente se entiende como revista femenina aquella publicación dirigida a un público formado por mujeres, en la que se tratan temas que está supuestamente más capacitado para decodificar el mensaje merced a la mayor identificación, interés, permeabilidad y su receptividad con el otro producto; en otras palabras, la temática también se considera "femenina" $(1999,311)$.

Según Juana Gallego, la prensa femenina está constituida por "publicaciones pensadas y dirigidas fundamentalmente a las mujeres, centradas en el ámbito de lo privado y cuya temática, enfoque y lenguaje utilizado se refiere y define lo que es ser mujer, hoy por hoy, en nuestra área cultural” $(1990,49)$.

El ámbito de lo privado debe interpretarse desde las actividades desarrolladas y administradas por mujeres. El discurso social ha distinguido la distribución de los espacios asignando funciones según el género. La esfera intíma o familiar suele estar representada por la mujer, mientras que la esfera pública la desempeña el hombre. Bajo esta perspectiva, Juana Gallego no duda en considerar que la prensa de información general está protagonizada por el hombre. En el caso de las mujeres, existen tres tipos de publicaciones clasificadas desde la perspectiva de prensa femenina siendo las siguientes.

- Revistas especializadas en divulgación y orientación. Están focalizadas en una serie de temas de la esfera doméstica como son la maternidad, la salud o la moda. Las revistas divulgadoras adoptan el papel de asesoras y consejeras ofreciéndoles sugerencias de interés a las lectoras.

-Revistas especializadas en servicios. Publicaciones muy específicas, con una temática definida. Es el caso de revistas de cocina, decoración, costura y bordado de prendas en casa y otras labores que tienen que ver con el ámbito doméstico. En general son publicaciones prácticas que no incluyen temas diferentes que aparecen en la portada.

-Revistas femeninas de información general. Contienen las típicas secciones y contenidos que contribuyen a estereotipar la información para mujeres. En torno a estas revistas, Gallego Ayala (1990) crea un concepto llamado trinomio al considerar que belleza-amor-hijos centran el discurso de las revistas femeninas de información general. A esa representación habría que sumar la moda como actor imprescindible que ayuda a mostrar las múltiples facetas estéticas que puede adoptar una mujer. Los cuatro temas tienen una interrelación porque a través de la belleza física (lograda gracias a la compra de productos cosméticos) y presentada con prendas de moda, la mujer encontrará el amor que le permitirá satisfacer su deseo innato: ser madre. 
En cuanto a la temática habitual de las revistas femeninas, Gallego Ayala (2008) habla del matrimonio belleza-hijos-amor que admite muy pocas variaciones u oscilaciones añadiéndose la moda como otro universo conceptual con identidad propia en estas publicaciones.

- Belleza. Mantenerse joven y en perfecto estado de belleza es el objetivo esencial para cualquier mujer, según los mensajes estereotipados que emiten las revistas femeninas. Conseguir que el cansancio físico y mental pasen a un segundo plano mediante terapias de choque, intervenciones quirúrgicas y tratamientos costosos es el nuevo ideal a seguir.

-Amor. Las relaciones afectivas, conyugales, la psicología afectiva, la educación sexual y la vida familiar son algunos de los temas más recurrentes en las revistas femeninas, sin olvidar un contenido específicamente creado para ofrecer consejos de seducción y métodos anticonceptivos.

como el lugar en el que pasar largas jornadas de felicidad y amor en compañía de los niños. El hogar se presenta como un espacio idealizado en el que cambiar la decoración al mismo ritmo que la lectora compra nuevas prendas con el inicio de cada temporada.

- Moda. La selección, edición y presentación de las tendencias de moda en cada revista de moda no es baladí, sino que responde a los criterios editoriales imperantes en cada grupo mediático responsable de la edición de la revista.

Plaza (2005) también considera la sexualidad como un universo temático con presencia destacada en las revistas femeninas. En publicaciones dirigidas a un público más juvenil como Glamour o Cosmopolitan, el sexo se vincula a la compra de prendas de lencería, productos cosméticos para resaltar el pecho, ocultar la celulitis o destacar los glúteos, además de la educación sexual mujer-hombre y viceversa. La sexualidad sigue mostrándose bajo una perspectiva paternalista con un sentimiento de romanticismo personalizado en la mujer frente al desapego del hombre.

El grueso del mensaje comunicativo que transmiten estas revistas es que la mujer debe consumir ya no para complacerse a sí misma, sino para gustar a los demás, en este caso, al hombre. Los cuidados físicos, la atención y el tiempo dedicado a la estética y la importancia de mostrar siempre un aspecto radiante son condicionantes atribuidos de forma diferente según el sexo. Para los hombres no hay obligaciones al respecto (aunque desde el nacimiento de la metrosexualidad cada vez hay más hombres que adoptan una serie de cuidados físicos y estéticos muy rígidos), frente a la tiranía característica de las mujeres. 
Otra de las características que mejor definen a las revistas es la atemporalidad en los contenidos. Santa Cruz y Erazo (1980) ya notaban hace 20 años que la prensa femenina abordaba los temas desde una perspectiva ahistórica e incluso estática. Los autores señalaban que apenas existían diferencias formales y de contenido entre los diferentes ejemplares editados por las diversas revistas femeninas generándose una descontextualización de la realidad inmediata no solo en nuestro país, sino en cualquier cabecera de moda y belleza presente en otros países europeos.

En ese sentido, para Schroeder (1981) las revistas dirigidas a mujeres presentan los temas de siempre. En opinión de este autor, la temporalidad con la que los medios de comunicación femeninos presentan los contenidos a tratar pone de relieve una evidente diferencia en comparación a la prensa generalista, más enfocada en publicar temas de interés para los lectores masculinos.

\subsection{Historia de las revistas objeto de estudio. De la dirección a la edición de la publicación}

Para la realización de la presente investigación se han escogido diferentes revistas femeninas especializadas en moda como son Telva, Vogue y Elle. La elección de estas publicaciones no es casual sino que responde a diferentes criterios de carácter histórico y temporal. Por una parte, Telva es una revista editada desde 1963 en España.

Considerada la década del periodismo femenino en España, Telva nació en un momento en el que la mujer española daba tímidos pasos por incorporarse al mercado laboral. La publicación fue creada por Sarpe (Sociedad Anónima Prensa y Ediciones), una editorial cercana al Opus Dei.

La primera directora de la revista, Pilar Salcedo, dejaba claro la línea ideológica de la publicación desde la página de su primer editorial donde señalaba que "soplan por el mundo corrientes de renovación, de desarrollo económico, se abren a la mujer nuevos horizontes y es preciso vivir a la altura de las circunstancias. Eso de "los derechos de la mujer" suena bien pero hay que estar a las duras y a las maduras. Le es preciso estar bien informada para que, al aprender los derechos, entienda en ellos el deber de trabajar -a escala europea-con una mayor seriedad y eficacia" (Gallego Ayala, 1990, 67).

Telva ha realizado muy pocos cambios a lo largo de su trayectoria como medio de comunicación contando con mujeres en la edición y dirección desde el primer ejemplar. La revista ha estado (y está) dirigida por mujeres: Pilar Salcedo (1963-1970), 
Covadonga O'Shea (1970-1997), Nieves Fontana (1997-2010) y Olga Ruiz (2010actualidad).

En 1970, Pilar Salcedo es sustituida por Covadonga O'Shea, numeraria y miembro activo del Opus Dei, además de ostentar la dirección de la revista durante más de tres décadas. Durante los primeros años en el cargo, O'Shea continúo con la salvaguarda de los valores tradicionales de la revista en cuanto a selección de prendas de moda y reportajes periodísticos. La etapa de Covadonga O'Shea será especialmente recordada por la creación de los premios de moda internacional T de Telva en 1991 (posteriormente se crearon los premios T de Telva de la belleza).

Nieves Fontana sucedió en la dirección a Covadonga O'Shea en 1997. Tras formar parte de la redacción de Telva durante más de 30 años, Fontana logró que la revista Telva batiera su propio récord en cuanto a volumen de ejemplares vendidos, en concreto, 200.000 (en 2006). Ese mismo año salía al mercado la versión pocket de Telva a un precio de venta de 1,95 euros.

Entre 2010 se incorpora a la dirección de la revista Olga Ruiz. En los últimos ocho años, Telva ha dado el salto a las nuevas tecnologías creando la edición online de la revista, multiplicando su visibilidad en redes sociales y alojando diferentes blogs. La revista ha ido adaptándose a los cambios característicos de la sociedad en cuanto a consumo de productos periodísticos volviéndose más atractiva.

En el caso de Elle (1986) y Vogue (1988), ambas publicaciones llegaron a España en plena transición democrática. La década de los 80 representa por lo tanto el aperturismo español hacia el exterior, no solo en términos periodísticos, sino también en materia económica y cultural.

En 1986, un acuerdo entre Ediciones Universales y Hachette Filipacchi hizo posible el nacimiento de Elle España, la tercera edición internacional después de Elle UK y Elle USA (ambas creadas en 1985). Elvira Aguilar fue la primera directora de la revista. Desde 1986 hasta 1988, Elvira Aguilar dirigió la revista para dar paso en 1988 a la periodista María Luisa Malibrán. La nueva directora convirtió la publicación en una alternativa viable en cuanto a términos de audiencia y público se refiere. En 1988, Ediciones Universales desaparece y Hachette Filipacchi consigue así el $100 \%$ de la revista. A finales de los ochenta el resto de revistas de origen internacional llegaron a España.

Desde 1993 hasta 2001, Susana Martínez fue la directora de la revista Elle. A lo largo de 17 años, Susana Martínez modernizó el contenido de la revista dotándola de un formato más sencillo, aumentando el número de páginas dedicadas a moda, dándole protagonismo a las fotografías de cuerpo entero e incluyendo temas sociales como la violencia doméstica, la desigualdad laboral o el acoso en el trabajo. 
Tras la marcha de Susana Martínez en 2001, el equipo de Hachette Filipacchi nombró a Benedetta Poletti nueva directora de la revista, cargo que mantiene en la actualidad. Al frente de Elle, Poletti ha acometido grandes retos periodísticos. En 2007, la revista doblegó esfuerzos en la estrategia digital relanzado la edición online de la publicación. Algunos de los retos acometidos por Poletti han sido la creación Elle pocket (o de bolsillo) de la revista a un precio de 1.95 euros.

Por su parte, según datos obtenidos del último informe elaborado por el Estudio General de Medios (febrero-noviembre 2017), la revista Vogue es la cuarta revista más leída en nuestro país con una media de 719 lectores mensuales, siendo además la primera revista más demandada dentro del segmento de las revistas especializadas en moda y tendencias femeninas.

Aunque la edición española nace a finales de la década de 1980, en concreto en 1988, el grupo Condé Nast ya realizó un primer intento fallido por establecerse en nuestro país. La primera directora de la revista fue Ana Puértolas. En 1994, Daniela Cattaneo adquiere la responsabilidad de dirigir Vogue España. Hasta 2001, momento en el que esta editora de origen italiano es sustituida por Yolanda Sacristán, Cattaneo acometerá importantes retos que ayudaron a consolidar la revista Vogue en nuestro país. El compromiso por la moda patria, el apoyo a los diseñadores nacionales y la difusión de noticias relacionadas con las tendencias de moda mostradas por las marcas de lujo internacional fueron algunas de las consignas de Daniela Cattaneo como editora de Vogue.

Yolanda Sacristán acometió uno de los retos más importantes de la publicación; la conversión digital. Al igual que el resto de publicaciones del sector, Vogue se lanzó a la digitalización de los contenidos mostrando en la edición online de la revista diferentes contenidos con una frecuencia de actualización continuada. En los últimos diez años, la publicación ha aumentado el número de páginas destinadas a la información, además de realizar diversas modificaciones en la maqueta de diseño, tanto en la presentación de los contenidos como en la estructuración de las secciones de la revista. Desde enero de 2017, Eugenia de la Torriente (ex directora de la revista Harper's Bazaar, ex editora de moda del diario El País y ex redactora jefe de El País Semanal) es la nueva directora de la revista es sustitución a Yolanda Sacristán. 


\section{Objetivos, hipótesis y metodología}

Los objetivos son imprescindibles en cualquier investigación que se realice. En el caso del presente trabajo, se han establecido como objetivo general y objetivo específico los siguientes:

- Objetivo general. Analizar el contenido mostrado por las revistas objeto de estudio para esclarecer si las unidades temáticas descritas por diversos autores tienen presencia mayoritaria o no en las publicaciones escogidas.

- Objetivo específico. Estructurar por familias de contenido, cuáles son los temas más difundidos y que realmente contribuyen al empoderamiento de las lectoras, frente a los contenidos que refuerzan la imagen encorsetada de la mujer.

De igual forma, la investigación no podría entenderse sin la formulación de hipótesis de partida. Cualquier ensayo, estudio o análisis de carácter científico debe acompañarse de hipótesis o planteamientos establecidos antes de comenzar el trabajo propiamente dicho. En el caso de la presente investigación se han establecido las siguientes hipótesis.

- H1. Las revistas de moda empoderan a las mujeres al difundir contenidos de interés para las lectoras más allá de las noticias de moda o belleza.

- H2. Las revistas de moda analizadas realizan un completo ejercicio de calidad periodística al garantizar el contraste de fuentes y el uso de tecnicismos.

Por otra parte, la metodología escogida para la realización de la investigación es de tipo deductivo-inductivo al tratarse de un estudio empírico. En el transcurso del trabajo se ha utilizado el análisis de contenido, herramienta empleada en un buen número de investigaciones realizadas en el ámbito de las Ciencias Sociales.

Para determinar que las mujeres dirigen (en su mayoría) las principales revistas de moda y tendencias editadas en España no es necesario usar ninguna herramienta metodológica al ser un hecho más que evidente. Sin embargo, la finalidad del análisis de contenido en este estudio planteada por los autores va mas allá. La utilización de esta técnica permitirá mostrar diferentes parámetros esenciales como son los siguientes: estudio del tipo de información editada por las revistas escogidas focalizando la atención en las unidades temáticas más repetidas, cuantificación de de páginas publicitarias frente al contenido informativo y el tratamiento que reciben los textos periodísticos desde la perspectiva de la calidad periodística con diferentes elementos como el contraste documental, la diversidad de fuentes de información y el uso de tecnicismos, además de comprender el impacto que generan los mensajes en las audiencias objetivo.

En el curso de la investigación se ha creado una muestra que responde a dos criterios. Por una parte, un componente relacionado con el contenido, y de otra parte, un factor de carácter temporal analizándose tanto los números de febrero y septiembre de 2017 
como los suplementos especiales de tendencias de las revistas Telva, Elle y Vogue coincidiendo con el lanzamiento de las nuevas colecciones en las pasarelas internacionales.

La industria de la moda pasa por una continua transformación pero sigue siendo fiel a la dualidad temporal en cuanto a la presentación de nuevas tendencias de moda. Por este motivo, es imprescindible determinar qué contenidos (independientemente de los textos que recogen información sobre moda) se muestran con mayor frecuencia en los números analizados de las tres revistas escogidas y qué rasgos de calidad están presentes mediante la aplicación de una ficha de variables que se mostrará más adelante.

Respecto al análisis de contenido, Piñuel (2002) considera que esta técnica es un conjunto de sistemas de comprobación de hipótesis que deben aplicarse tanto a mensajes como a textos para extraer datos relevantes. El análisis de contenido no puede ser solo cualitativo porque no existen métodos de análisis fijados en un marco teórico previo en el que se especifiquen todas las unidades de análisis utilizadas. "El análisis de contenido está basado en casos, a diferencia de la aproximación cuantitativa, que está basada en variables. La cualitativa es holística, en tanto que lo individual es estudiado y observado como una completa entidad, en la convicción de que cada humano es más que la suma que da por resultado la colección de todas las partes (en este caso serían las variables). El objetivo del análisis es comprender a las personas y no las relaciones entre las variables" (Corbetta, 2003, pgs. 290-291).

Para Bordas (2015) el origen de esta técnica de trabajo está en la hermenéutica, es decir, una tradición filosófica clásica que interpretaba textos y documentos procedentes de varias culturas. A su vez, la hermenéutica no puede entenderse sin las aportaciones de Platón y Aristóteles. El primero fue precursor en la interpretación de los mitos. Por su parte, Aristóteles desarrolló una sistematización de los procedimientos lógicos.

De otra parte, "el análisis de contenido ha sido objeto de estudio y exploración durante varias décadas. No han sido pocos los autores que han dedicado unas líneas a destacar la importancia que tiene este método tanto en la investigación social como en diferentes disciplinas relacionadas con el estudio de las ciencias sociales. De igual forma, esta técnica también se ha usado para estudiar las aportaciones hechas por otros autores con intenciones diversas. A veces, el análisis puede plantearse como un procedimiento destinado a contrastar una hipótesis, mientras que en otros casos es empleado como herramienta para descubrir diferentes características ocultas o poco visibles en los textos. Además de utilizarse para comprender el alcance que tiene la 
información presente en documentos escritos o sonoros, el análisis de contenido también es válido en sistemas digitalizados" (Luque, 2017, 67).

Krippendorff explica que el análisis de contenido "puede llegar a convertirse en una de las más importantes técnicas de investigación de las ciencias sociales. Procura comprender los datos, no como un conjunto de acontecimientos físicos sino como fenómenos simbólicos, y aborda su análisis directo". El contexto actual de los medios de comunicación -como plataformas creadoras y difusoras de contenidos- atraviesa un momento de cambios, tanto en el paradigma como en la forma. Las nuevas formas de comunicación adoptan el formato de redes sociales y se expanden por medio del poder de millones de usuarios presentes en cualquier lugar del mundo.

Junto a Krippendorff otros autores han contribuido al estudio del análisis de contenido. Lazarsfeld y Berelson (1948) aportaron diferentes puntos de vista hasta mediados del siglo XX con el objetivo de encontrar una definición exacta del término. "Es una técnica de investigación destinada a formular, a partir de ciertos datos, inferencias reproducibles y válidas que puedan aplicarse a diferentes contextos". (Krippendorff, 1998, 28).

Para obtener una información concluyente sobre los diversos aspectos de análisis de contenido, los autores han creado una ficha o tabla de variables en las que se han escogido diferentes variables tendentes a medir aspectos relacionados con la calidad periodística (contraste documental, uso de fuentes de información, presencia de tecnicismos) y con el contenido elaborado por el equipo de redacción de las tres revistas estudiadas. La aplicación de la ficha de variables en las tres publicaciones seleccionadas no solo ayudará a determinar si las revistas empoderan realmente a la mujer española, sino que también ofrecerá información sobre la adecuación o no de los textos a la correcta praxis periodística. A continuación, se muestra la ficha de análisis.

\section{Modelo con variables.}

- Nombre de la publicación y periodicidad.

- Número de páginas dedicadas a la información y a la publicidad. Es evidente que la publicidad en los medios de comunicación resulta esencial para garantizar en parte la viabilidad económica del medio. Aunque prácticamente todos los medios especializados presentan páginas publicitarias, es en las revistas, y en concreto en las publicaciones de moda, donde se aprecia de forma más evidente la importancia de la publicidad en el contenido de la revista.

- Unidades temáticas más tratadas en la publicación. De forma general, las revistas analizadas tienen como principal objetivo difundir contenidos relacionados con la moda. En paralelo, las publicaciones incluyen otros contenidos adicionales y que 
resultarán determinantes para comprobar el grado de empoderamiento que las revistas para mujeres pretenden conseguir. Tras analizar las tres publicaciones anteriormente descritas, se presentan las unidades temáticas mayoritarias presentes en los volúmenes analizados.
O Moda
o Belleza
o Relaciones afectivas o de pareja
o Otros

- Calidad periodística de la información. Determinar la calidad periodística de la información es esencial en cualquier publicación. En el caso de las revistas especializadas, en este caso moda, aún más. Lograr que la formación de audiencias críticas sea una realidad mediante contenidos periodísticos elaborados según los criterios de objetividad, concisión y calidad no es tarea sencilla en la actualidad. La divulgación informativa forma parte del periodismo especializado siendo la formación de audiencias críticas una de las máximas de esta disciplina. Tras considerar diversos factores tendentes a garantizar la calidad, los investigadores han escogido tres elementos esenciales descritos a continuación.

o Contraste documental del contenido. Junto con el resto de ítems de calidad que a continuación se presentan, el contraste documental del contenido es uno de los parámetros más importantes que existen en el entorno periodístico para determinar si la información presentada ante los lectores se ajusta a los criterios de calidad o no.

o Diversidad de fuentes de información. No es objeto de la presente investigación desglosar los diferentes tipos de fuentes de información existentes según las clasificaciones dadas por expertos en periodismo especializado. Sin embargo, sí es necesario detectar la presencia o ausencia de varias fuentes de información en los textos analizados que aporten una identidad propia al contenido.

o Uso de tecnicismos. La utilización de tecnicismos es inherente a cualquier ámbito de especialización periodística. En el caso del periodismo de moda, con frecuencia los redactores y editores emplean un vocabulario muy concreto compuesto en la mayoría de las veces por extranjerismos y tecnicismos de moda.

Como puede verse, la ficha de análisis contempla diferentes aspectos tendentes a elaborar un estudio que permita entender los contenidos mostrados con más frecuencia en las revistas analizadas para empoderar a las lectoras o perpetuar la imagen estereotipada de las mujeres, además de establecer el porcentaje de páginas 
dedicadas a la información frente a la publicidad, sin olvidar las variables determinantes de la calidad periodística de los textos.

\section{Medición de resultados}

El presente epígrafe muestra los resultados obtenidos en cada una de las tres revistas objeto de estudio tras la aplicación de la ficha de análisis presentada con anterioridad en el punto de objetivos y metodología. Los primeros resultados que se exponen provienen de la revista Telva, una de las publicaciones más notables del periodismo femenino en España.

Nombre de la publicación y periodicidad. Telva, mensual

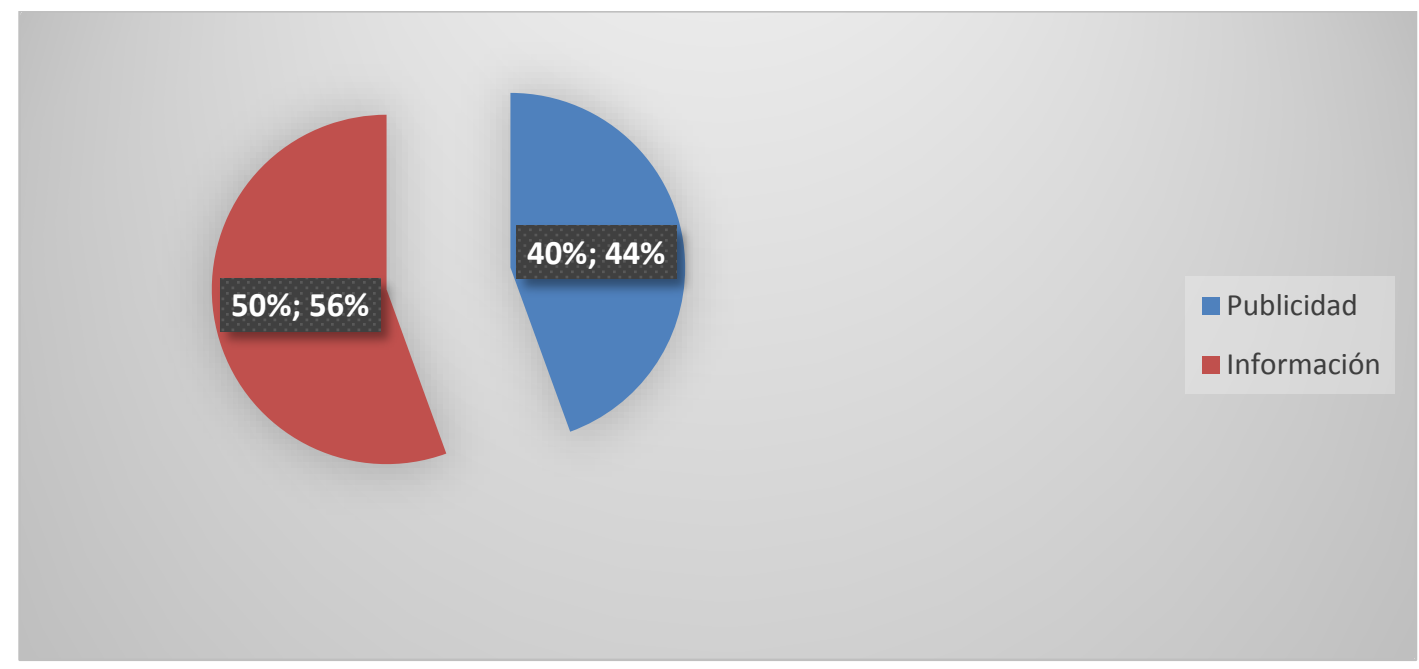

Gráfico 1. Número de páginas dedicadas a la información y a la publicidad

En el caso de la revista Telva, la publicación decida un $50 \%$ de las páginas a la información frente a un $40 \%$ de las páginas de la revista que son publicidad. Este porcentaje tan ajustado entre publicidad e información determina que la publicidad sea cada vez más importante en los medios de comunicación (no solo de moda). 
La inversión en publicidad es clave para garantizar la viabilidad económica de la revista. En el caso de Telva, la mayoría de las páginas de publicidad mostradas pertenecen a firmas de moda y lujo (representadas a su vez por grandes compañías o holdings internacionales), marcas de perfumería y productos de cosmética y belleza. Puede verse como la publicidad ya induce a perpetuar los patrones de comportamiento de la lectora al dejar poco margen a otras campañas de publicidad o anunciantes que no respondan a empresas de moda, cosmética y belleza.

Respecto a la información, la revista Telva realiza un despliegue de medios (al igual que el resto de las revistas analizadas) en el suplemento de especial tendencias. Es evidente el esfuerzo de la publicación en ofrecer a la lectora una revista adicional con el mismo número de febrero y septiembre debido al tamaño, extensión y cantidad de páginas de los suplementos de tendencias. La noticia y el reportaje son los dos géneros periodísticos mostrados con mayor frecuencia tanto en los dos suplementos escogidos para el análisis, como en el número de febrero y septiembre de la revista.

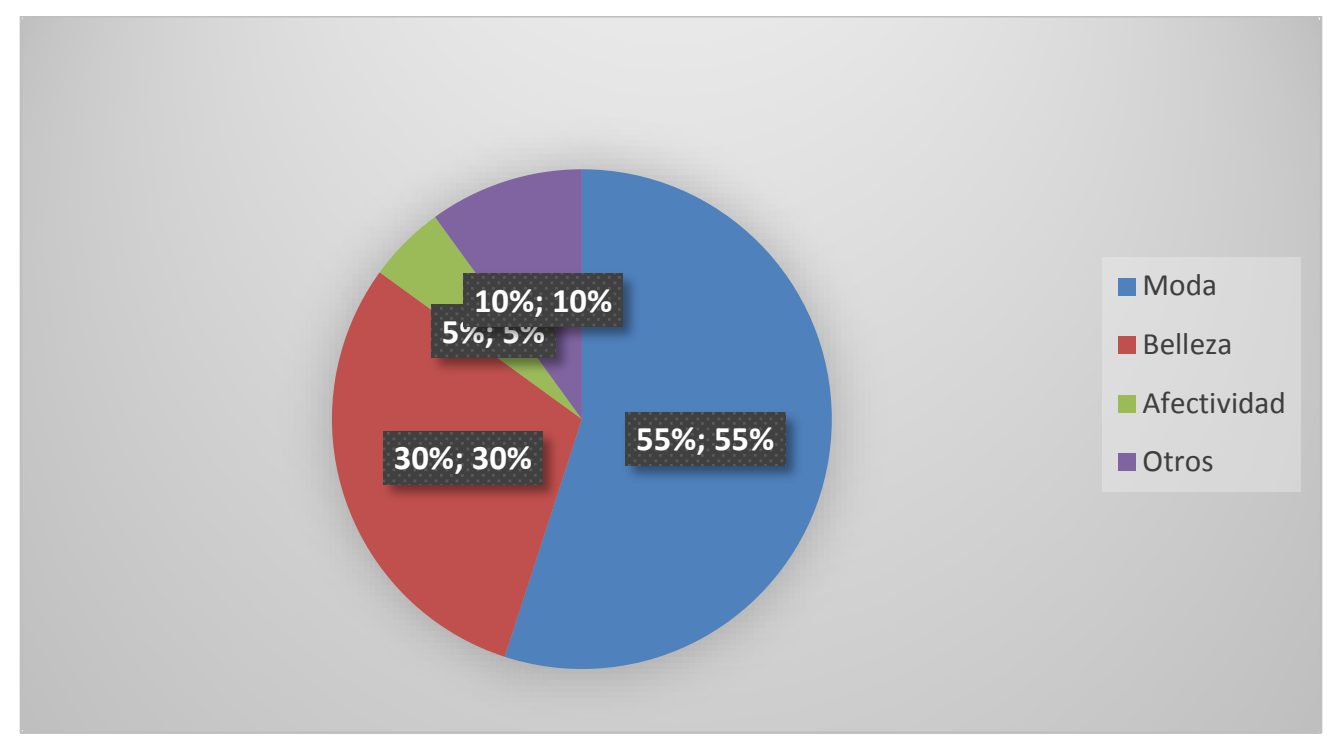

Gráfico 2. Unidades temáticas más tratadas en la publicación

Este gráfico es determinante para obtener más información sobre las unidades temáticas tratadas con más frecuencia en las revistas de moda objeto de estudio. Por una parte, con un 55\% la moda, es decir, las noticias, reportajes y crónicas relativas a las últimas novedades y tendencias de las marcas de la industria centran más de la mitad del contenido temático de Telva, seguido de un 30\% de contenidos relacionados con la cosmética, la belleza o la perfumería a través de reportajes y noticias que muestran cuáles son los últimos tratamientos lanzados al mercado para mejorar el aspecto físico de las lectoras. 
Con un discreto $5 \%$ aparecen los temas relacionados con la afectividad sexual de la mujer, es decir, la difusión de noticias que analicen posibles problemas o preocupaciones de las mujeres en torno al sexo o cómo prevenir enfermedades de trasmisión sexual. Finalmente, con un $10 \%$ aparecen los contenidos clasificados como Otros y que responden a noticias, reportajes y entrevistas sobre diversas temáticas como son la cultura, la economía, la política, la gastronomía o los viajes al contar con el testimonio de fuentes expertas en la materia que ceden la información a Telva.

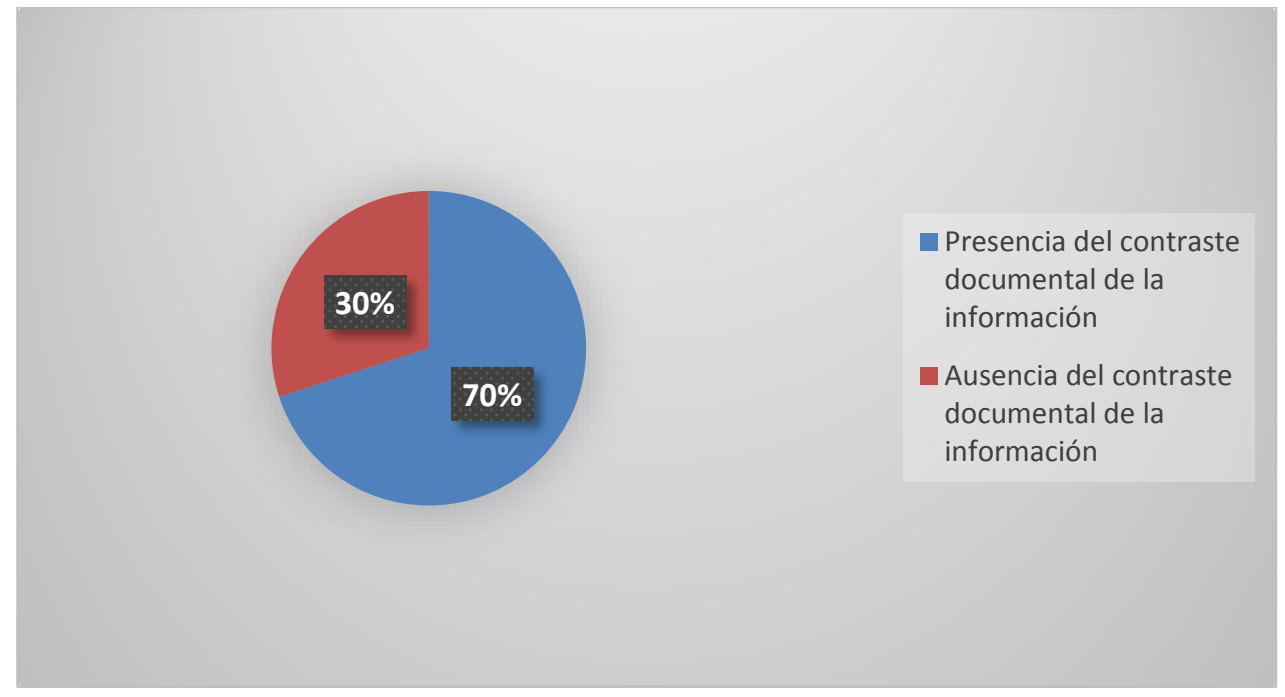

Gráfico 3. Calidad periodística de la información

Este gráfico es el primero de tres gráficos relacionados con la calidad periodística de la información mostrada en los números analizados de la revista Telva. Como puede verse, en un $70 \%$ de los textos analizados, el contraste documental de la información queda garantizado mediante la inclusión de diversas fuentes de información que aportan datos de carácter complementario a la información inicialmente mostrada por la revista. Frente al $70 \%$ de los textos contrastados, aparece un $30 \%$ de textos con información procedente de fuentes externas como agencias de comunicación o agencias de noticias que envían masivamente notas de prensa sobre diferentes acontecimientos de carácter noticioso. 


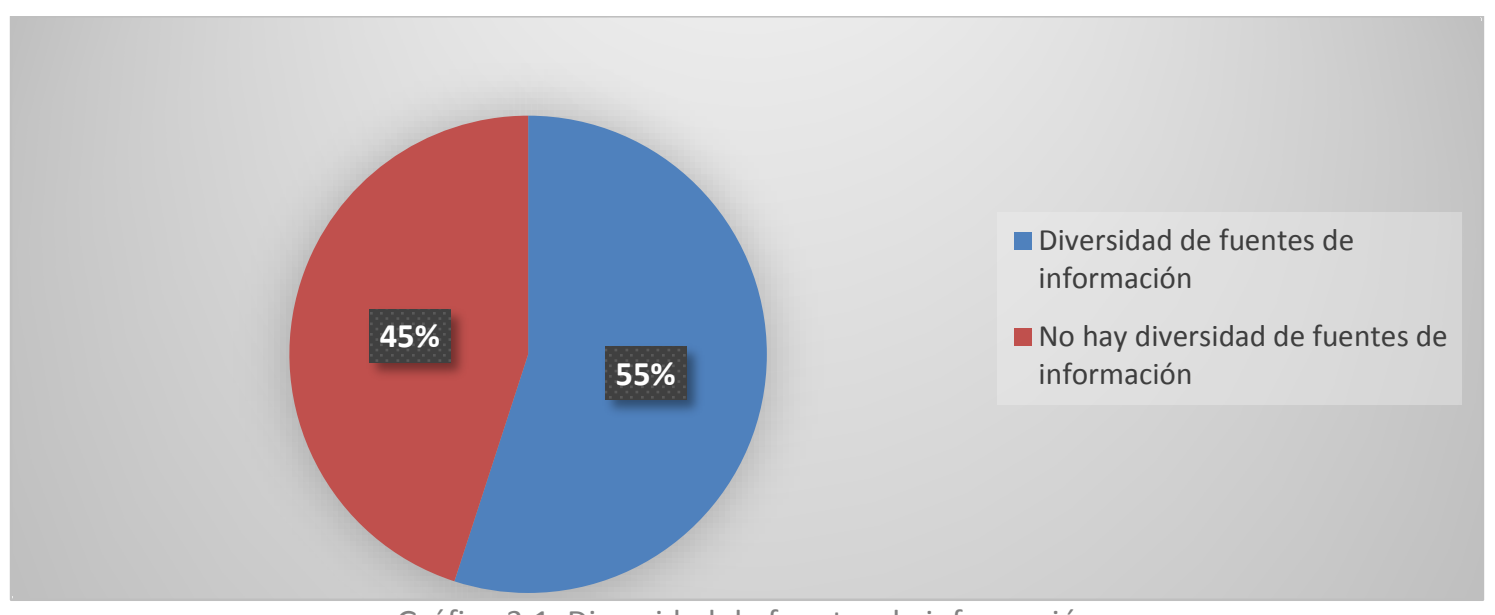

Gráfico 3.1. Diversidad de fuentes de información

Este es el segundo de los tres gráficos enmarcados en el parámetro de la calidad periodística. Después de analizar los ejemplares de Telva puede verse como en un 55\% de los textos mostrados, el equipo de redacción realiza una tarea de contraste documental mediante el uso de diversas fuentes de información de carácter profesional, es decir, fuentes expertas como diseñadores, modelos, actores, actrices, cantantes, escritores o médicos especializados en medicina estética, además de utilizar fuentes de carácter documental como referencias bibliográficas, libros, manuales y dossieres que dan como resultado una información creada gracias a la utilización de diversas fuentes de información. Sin embargo, en un $45 \%$ de los textos analizados, la diversidad de fuentes no es continua de forma que la revista aborda un hecho noticioso desde una perspectiva concreta sin ofrecer versiones alternativas o las visiones de otros actores implicados que puedan enriquecer la información.

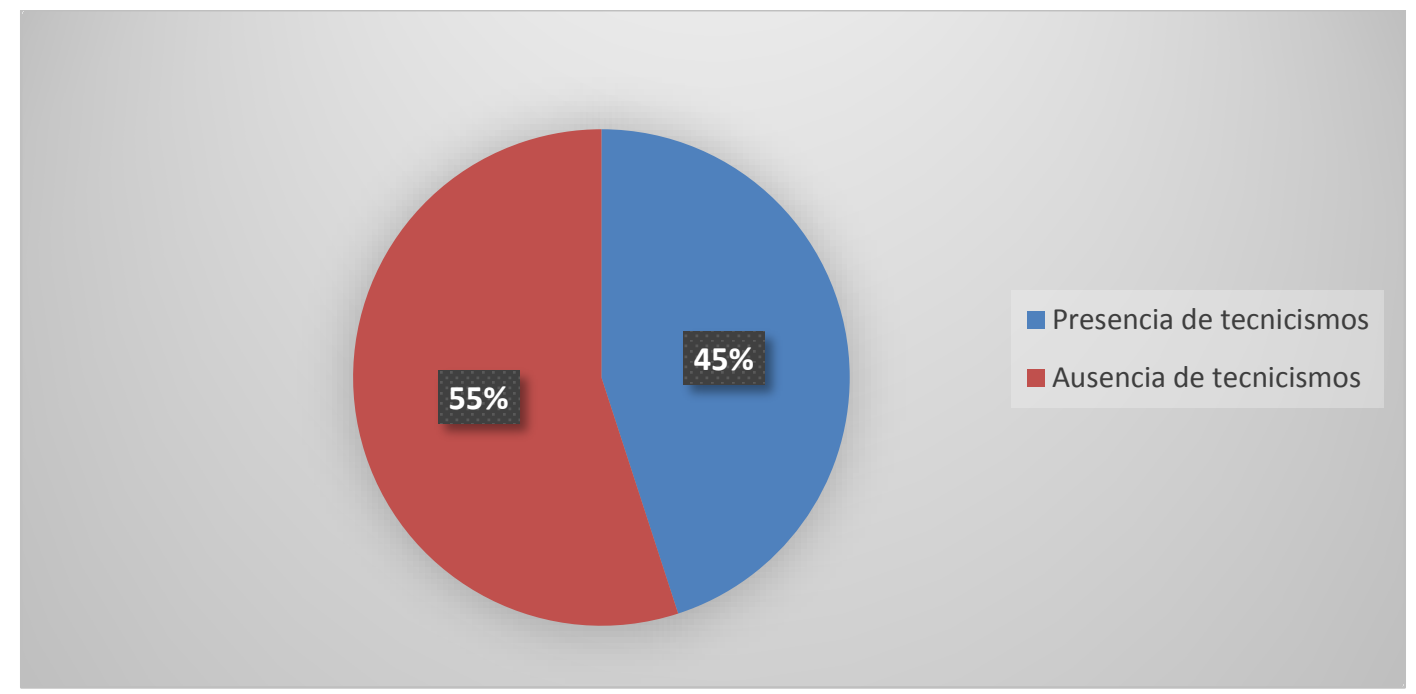

Gráfico 3.2. Presencia de tecnicismos

Este es el último de los tres gráficos relacionados con la calidad de la información en las páginas analizadas de la revista Telva. Como puede verse, en un $55 \%$ de los textos no aparecen tecnicismos relacionados con el periodismo especializado en moda. A 
diferencia de las otras revistas analizadas, el caso de Telva es particular porque la revista no muestra un especial interés en la utilización de palabras técnicas (en su mayoría procedentes del inglés o del francés) para explicar las nuevas prendas de ropa de tendencia o las claves de la temporada. En su lugar, el equipo de redacción de la revista utiliza términos o castellaniza los tecnicismos para mostrar una difusión de la información más amplia. Este porcentaje mayoritario es continuo en todas las páginas analizadas, frente a un $45 \%$ de los textos que sin incluyen tecnicismos. 


\section{Nombre de la publicación y periodicidad. Elle}

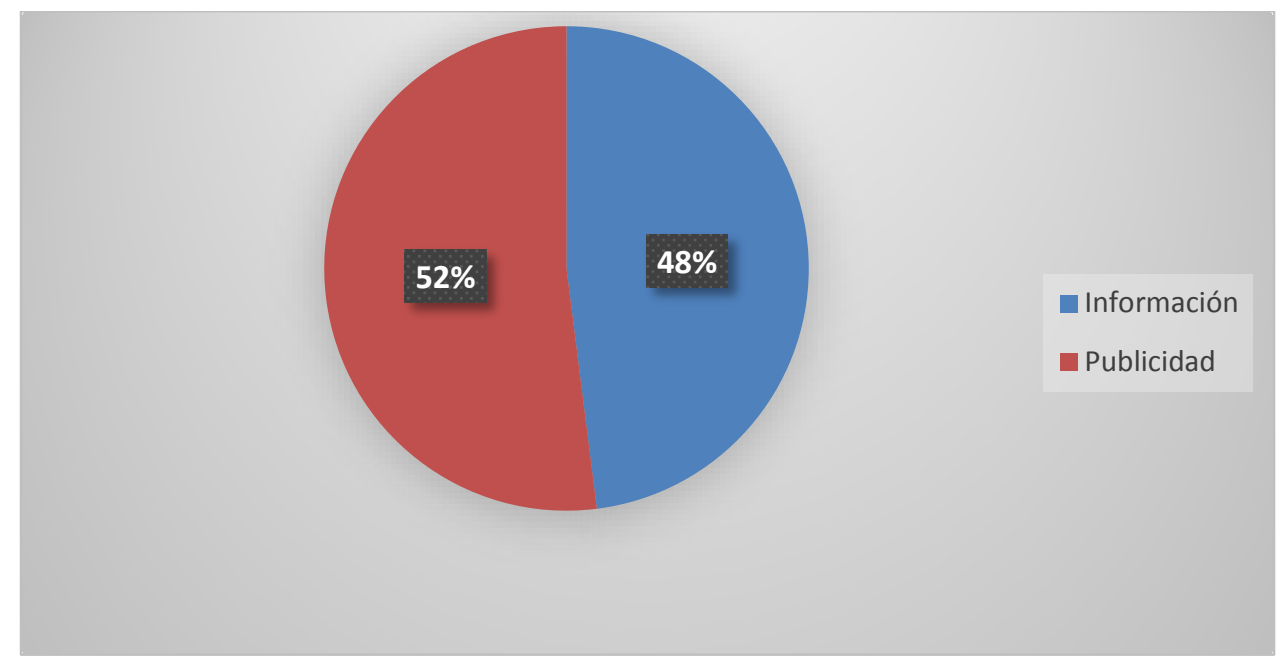

Gráfico 1. Número de páginas dedicadas a la información y la publicidad

Tal y como puede verse en este gráfico, el porcentaje de páginas que dedica la revista Elle a la información en los números analizados es del $48 \%$ frente al $52 \%$ de las páginas representadas por publicidad. Al igual que en el caso de Telva, se aprecia la presencia de importantes marcas de moda, cosmética, perfumería y joyería en forma de campañas de publicidad y en la inclusión de productos en reportajes, editoriales y bodegones de artículos convirtiéndose en objetos recurrentes para las lectoras de la revista. Respecto a la información, un $48 \%$ de los textos analizados representan piezas informativas en forma de noticias, reportajes o crónicas sobre diversos temas como son moda, cosmética, belleza presentando muy pocas variaciones temáticas.

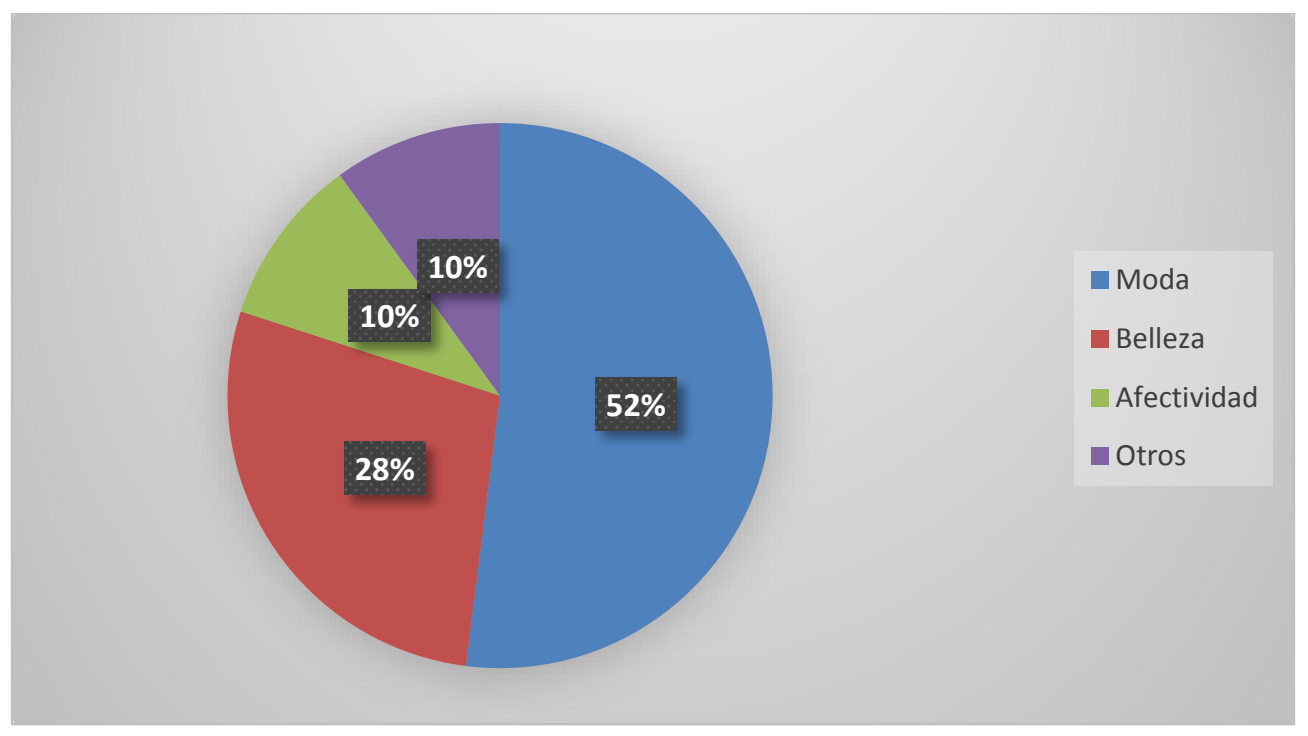

Gráfico 2. Unidades temáticas más tratadas en la publicación 
Este gráfico muestra los contenidos temáticos más frecuentes en la revista Elle. Tal y como puede verse, la moda ocupa con un 52\% la mayoría de los contenidos, seguido de la belleza con un $28 \%$, la afectividad con un $10 \%$ y otros contenidos con otro $10 \%$. La moda sigue siendo el contenido protagonista en la revista Elle con noticias, reportajes y crónicas que incluyen las últimas novedades del sector y mensajes apelativos al consumo de nuevos productos por parte de la revista induciendo a que la lectora adquiera las últimas tendencias con la finalidad de lucir cada vez mejor. Este mensaje también es compartido en las páginas dedicadas a belleza o cosmética incluyéndose todo un despliegue de mensajes que incitan a comprar nuevas cremas o productos para recuperar la silueta después de los excesos del verano. Tan solo un $10 \%$ de los contenidos se dedican a otras páginas como cultura, música o educación.

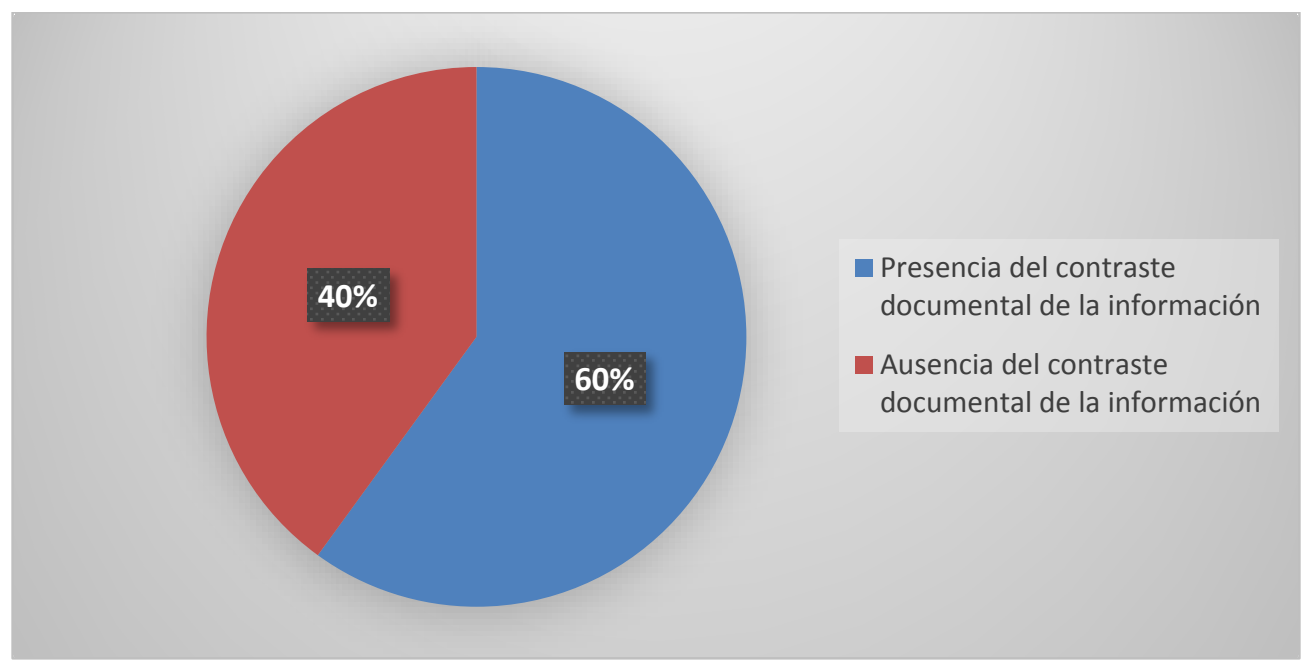

Gráfico 3. Calidad periodística de la información

Este gráfico muestra información sobre el contraste documental de la información de la revista Elle. Como puede verse, en un $60 \%$ de las páginas analizadas existe contraste documental de la información mostrándose páginas en las que el equipo de redacción de la publicación utiliza diferentes técnicas para garantizar que la información que publican es $100 \%$ veraz, frente a un $40 \%$ de los contenidos que se elaboran sin seguir un exhaustivo protocolo de contraste documental o de la información al tratarse por ejemplo de noticias que proceden de agencias de comunicación o de noticias y que facilitan la misma información a todos los canales bajo una distribución masiva de los contenidos. 


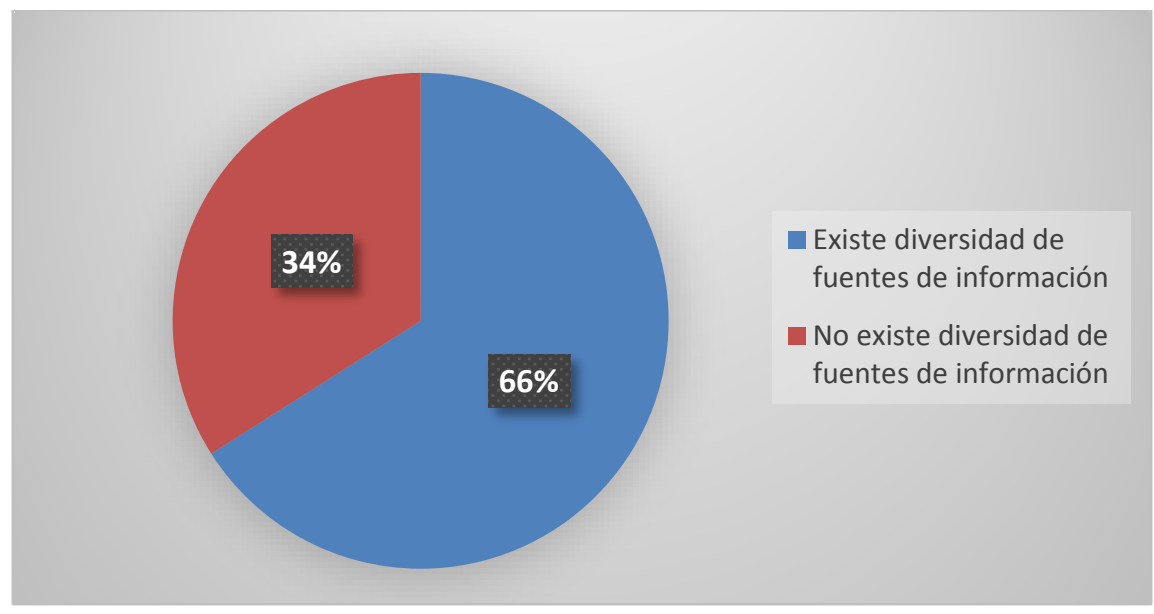

Gráfico 3.1. Contraste documental de la información

Este gráfico aporta información sobre la diversidad de fuentes de información utilizada por el equipo de redacción de la revista Elle en la elaboración y selección de los textos descriptivos de la revista. Tal y como puede verse, un $66 \%$ de los textos analizados en la presente investigación presenta una diversidad de fuentes de información mediante el uso de diferentes fuentes, bien sean de carácter personal, profesional, expertas, secundarias o documentales, frente a un $34 \%$ de los textos que no presentan un suficiente dominio o utilización de las fuentes de información más comúnmente utilizadas en una revista de moda como son las fuentes profesionales, expertas o documentales.

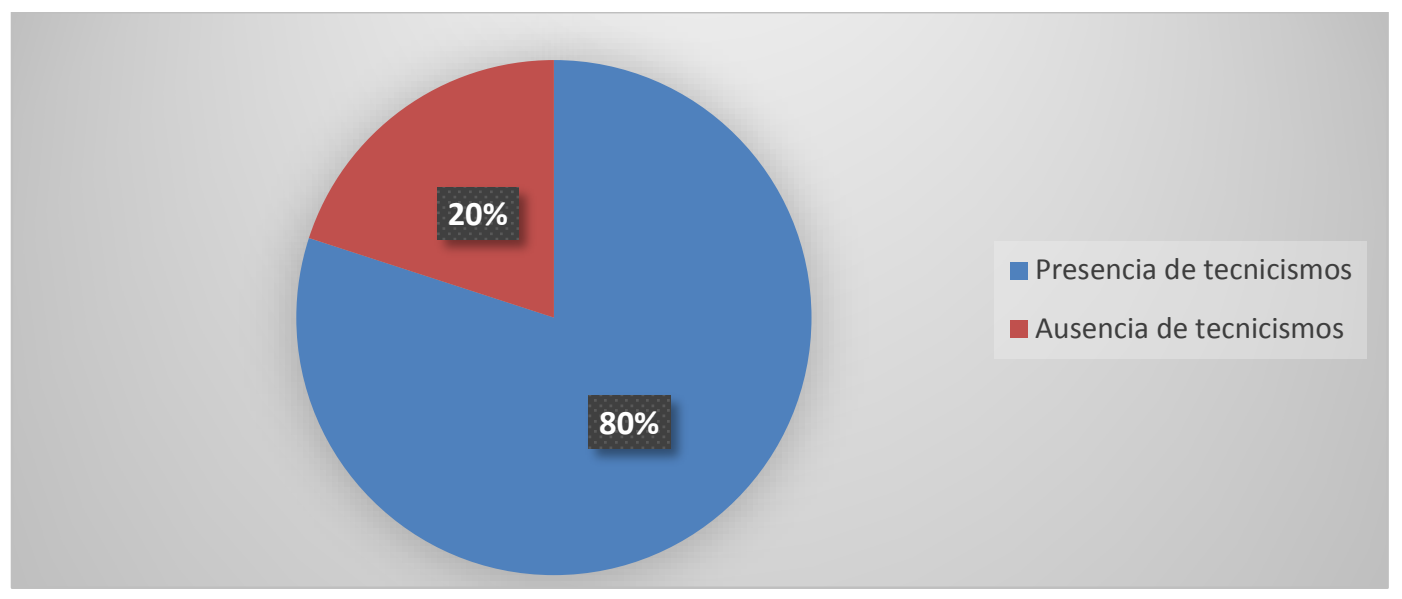

Gráfico 3.2. Diversidad de fuentes de información

Este es el último de los tres gráficos relacionados con la calidad de la información en las páginas de la revista Elle. Tal y como puede verse, un $80 \%$ de los textos analizados cuentan con tecnicismos diversos y ampliamente utilizados en publicaciones de moda como son jeans, pailletes, stilletos o blazer, es decir, extranjerismos que el equipo de redacción de la revista incluye con la misma naturalidad con la que los diseñadores de moda utilizan estos términos para explicar cuáles son las características generales de 
una nueva colección. Frente este porcentaje tan amplio, tan solo un $20 \%$ de los textos no tienen tecnicismos.

Nombre de la publicación y periodicidad. Vogue, mensual

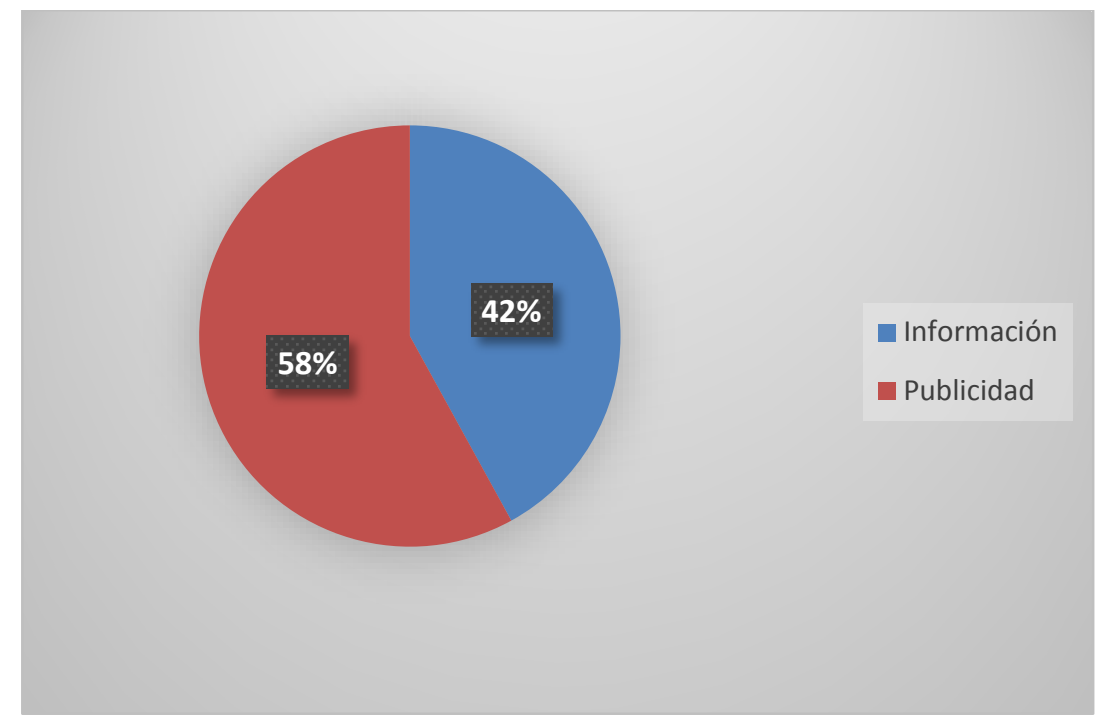

Gráfico 1. Número de páginas dedicadas a la información y a la publicidad

Este gráfico muestra la representación de páginas que Vogue dedica a la información mediante noticias, reportajes, crónicas o entrevistas, frente a la publicidad. La información tiene una representación del $42 \%$, frente a la publicidad con un $52 \%$. Es importante destacar este reparto entre información y publicidad porque las principales marcas de moda, belleza, cosmética y perfumería cuentan con presencia propia en las páginas de la revista Vogue mediante campañas de publicidad.

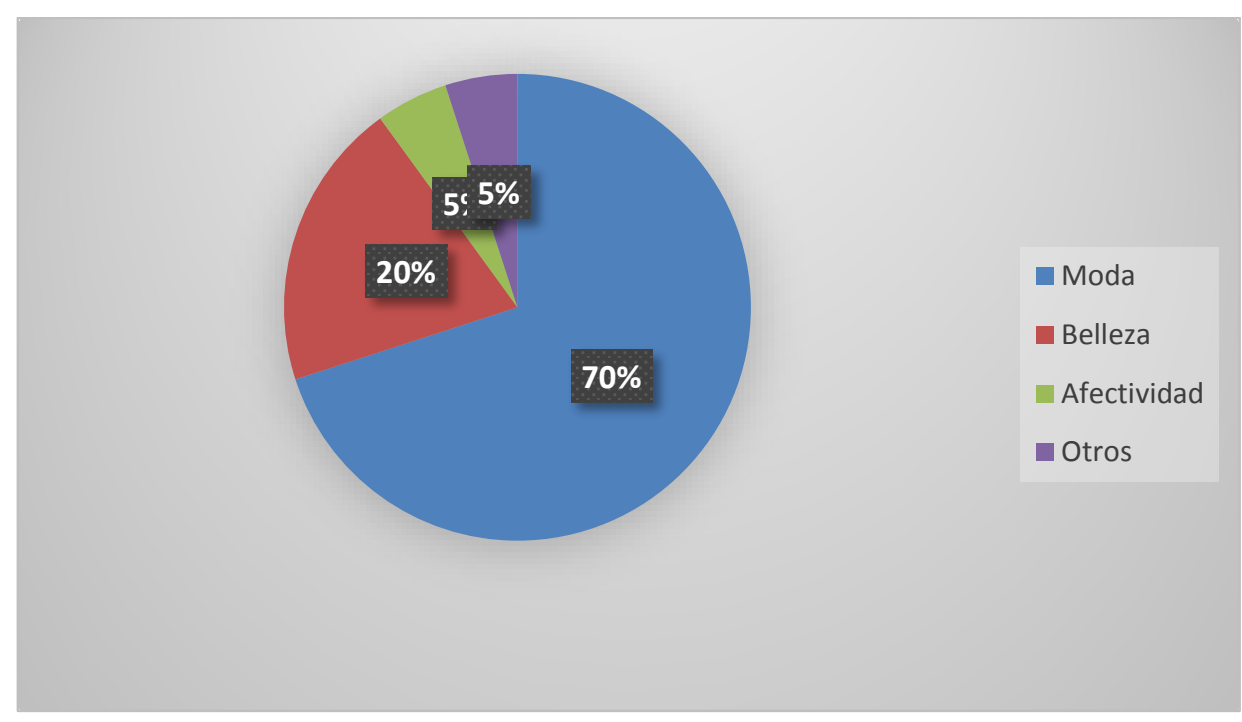

Gráfico 2. Unidades temáticas más tratadas en la publicación 
Con contenidos, la revista Vogue dedica un $70 \%$ de las páginas a mostrar las últimas tendencias, novedades y noticias relacionadas con la industria de la moda. No es de extrañar que para el equipo de redacción de Vogue la moda sea el contenido más importante porque la revista es conocida en todo el mundo como "la Biblia de la moda", es decir, como la publicación especializada en moda más importante dentro de la industria mediática.

Tras la moda, le sigue con un $20 \%$ los contenidos relacionados con la belleza, la cosmética y la perfumería mostrando los últimos tratamientos, novedades cosméticas y productos para la que la lectora mantenga en perfecto estado su cuerpo y rostro. Finalmente, con un $5 \%$ respectivamente aparecen la afectividad o relaciones de pareja y otros contenidos como por ejemplo literatura, novedades cinematográficas, gastronomía o cultura.

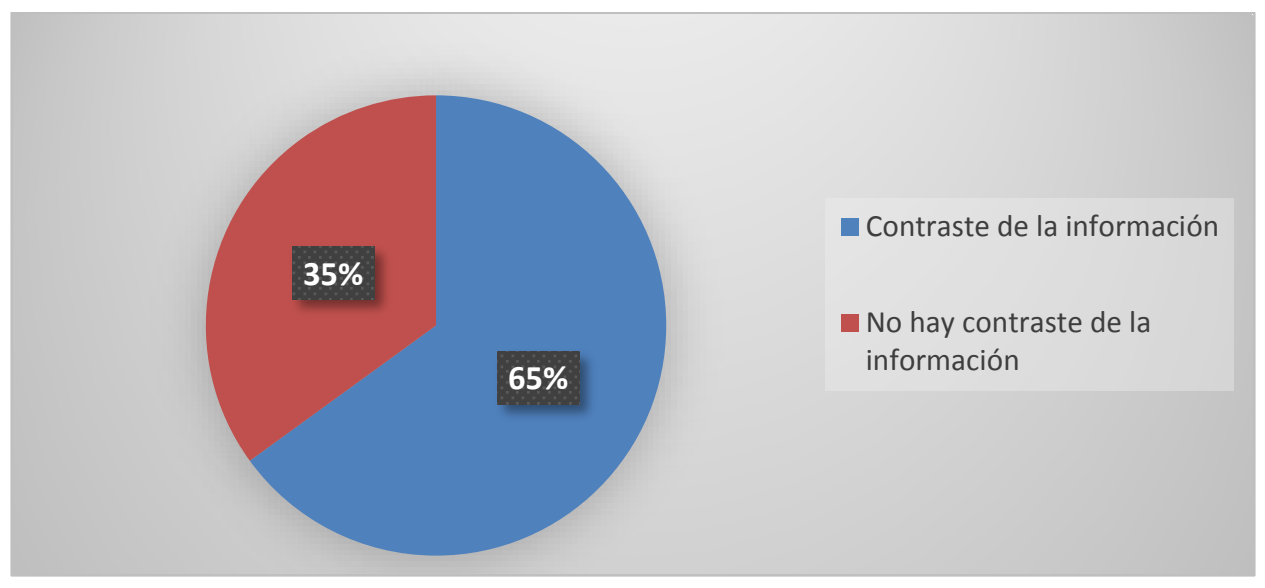

Gráfico 3. Calidad periodística de la información.

Este gráfico muestra información sobre el proceso de contraste documental de la información por parte del equipo de redacción de Vogue. Tal y como puede verse, en un $65 \%$ de los textos analizados existe un contraste evidente de la información utilizándose diferentes técnicas y herramientas para garantizar que la información mostrada en las páginas de la revista es $100 \%$ objetiva, frente a un $35 \%$ de los textos que carecen de suficiente contraste documental para garantizar la objetividad de la información.

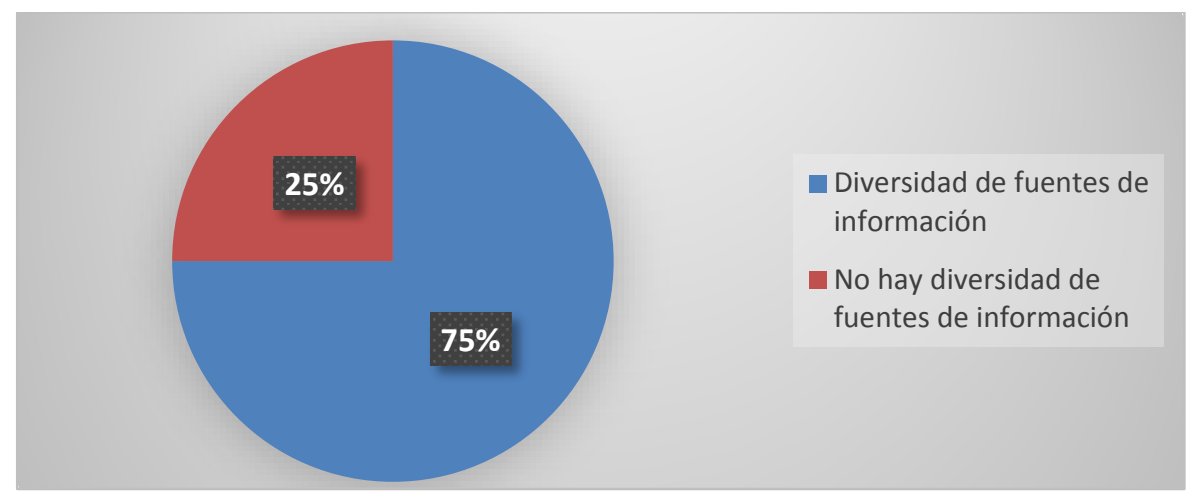


Este gráfico es otro de los más importantes de la investigación en lo que respecta a la revista Vogue. Puede verse como en un $75 \%$ de los textos analizados aparece una utilización continuada de las fuentes de información más empleadas en el periodismo especializado (fuentes personales, documentales, privadas, expertas, profesionales) para dar forma a la información teniendo como resultado la creación de textos periodísticos de gran calidad en forma y fondo. Frente a este amplio porcentaje, tan solo un $25 \%$ de los textos carece de un contraste adecuado en cuanto al uso de diversas fuentes de información.

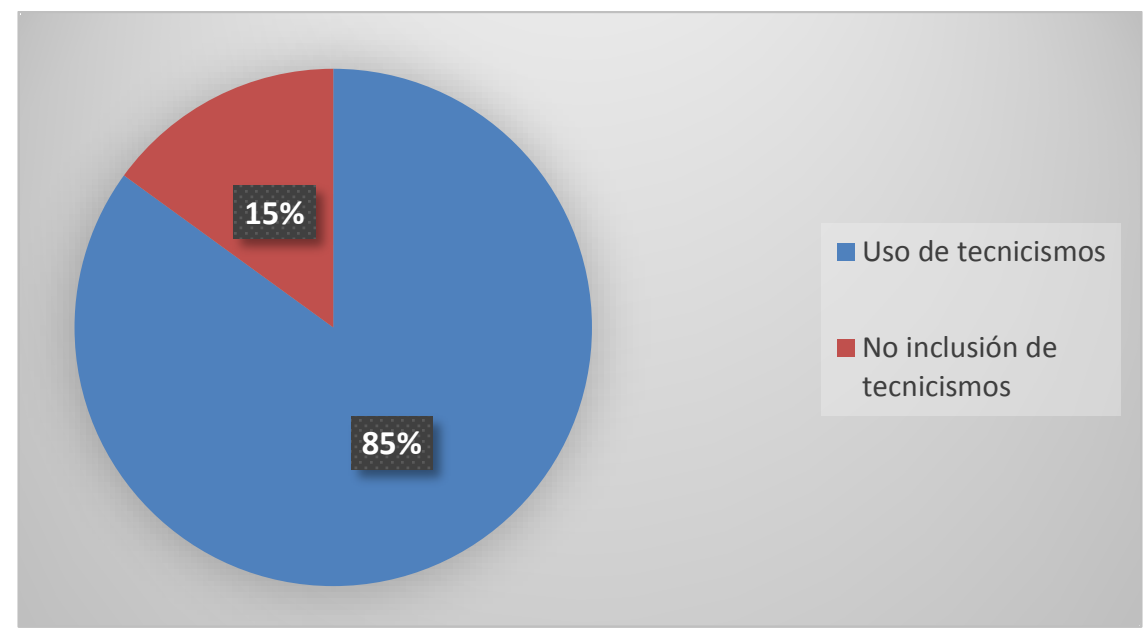

Gráfico 3.2. Presencia de tecnicismos

Vogue, al igual que la revista Elle, son dos publicaciones de origen internacional presentes en más de 20 países y con una vocación global por ofrecer noticias relacionadas con la moda a nivel mundial. Esta visión queda reflejada en el tratamiento de la información al incluir en la medida de lo posible diferentes tecnicismos y anglicismos muy frecuentes en la industria de la moda. Con un $85 \%$ de los casos, los textos analizados y presentados en la revista Vogue cuentan con diferentes tecnicismos en la mayoría de los casos fácilmente comprensibles para la lectora potencial de la publicación, frente a un discreto $15 \%$ de los textos que no cuentan con tecnicismos.

\section{Conclusiones}

Al comienzo de la presente investigación se establecieron diferentes objetivos e hipótesis para determinar si la presencia de las mujeres en la dirección y edición de las revistas de moda era suficiente para reforzar el empoderamiento de las lectoras 
femeninas mediante la difusión de contenidos que realmente consiguieran tal fin. La elección de la herramienta metodológica del análisis de contenido aplicada mediante el diseño de una ficha de variables previamente dispuesta sobre los números de febrero y septiembre más los suplementos de tendencias de la moda de las revistas Telva, Elle y Vogue ha determinado diferentes conclusiones pertinentes al respecto.

En primer lugar, aunque las mujeres tengan una presencia propia en los cargos de dirección y edición de contenidos en las revistas de análisis objeto de estudio, este hecho no coincide con la necesaria estrategia de empoderamiento que necesitan las mujeres hoy en día para equiparar su representación en una sociedad dominada por hombres. La difusión de contenidos clásicamente femeninos como las noticias de moda, las novedades de belleza y las relaciones afectivas entre hombres y mujeres centran la mayoría de universos temáticos de las revistas estudiadas.

Podría entenderse que la especialización en moda es precisamente la principal carta de presentación de estas publicaciones. Sin embargo, es imprescindible que sin perder la especialización periodística en moda, se incluyan contenidos más cercanos al ámbito intelectual como la cultura, la educación, el arte o la literatura frente al predominio excesivo de la información estrictamente femenina, o incluso noticias consideradas típicamente masculinas como la economía, la política o la cotización en el mercado de valores de empresas de moda. Por lo tanto, la primera hipótesis de partida de la investigación no se ha cumplido al establecerse que las revistas empoderan a las mujeres al difundir contenidos que van más allá de la moda o la belleza.

La representación de las mujeres en las páginas de las tres revistas analizadas es continúa pero esa representación sigue mostrando el papel tripartido de la mujer (esposa, ama de casa y trabajadora a tiempo completo) sometiendo a las féminas a una tiranía estética (con la difusión de novedades en consumo de moda y productos de belleza), física (con la irrupción de nuevas técnicas para lograr un cuerpo 10 en poco tiempo) y laboral. Por lo tanto, las revistas objeto de estudio difunden una línea de contenidos anacrónica en el tiempo al ofrecer mayoritariamente información estereotipada.

En segundo lugar, la calidad en términos de contenidos periodísticos es mayúscula, aunque la publicidad es clave para entender la viabilidad económica de las revistas. Salvo en el caso de Telva, publicación de origen nacional, fiel a sus códigos creativos y fundacionales, Elle y Vogue muestran mayor predominio de la publicidad que de la información (máxime en los números de febrero y septiembre y en los suplementos de tendencias). Los números analizados son clave para entender no solo la difusión de las tendencias que vestirán las mujeres de casi todo el mundo, sino para cuantificar la presencia o ausencia de determinas marcas de moda en las páginas de las revistas analizadas. Una industria tan aparentemente caprichosa y banal como es la moda genera millones de euros anuales en términos de ingresos publicitarios. Conscientes de 
esta realidad, las marcas de moda y lujo invierten notables cantidades de dinero en campañas de publicidad con el objetivo de llegar al target potencial de las revistas.

De otra parte, el contraste documental y el uso de fuentes periodísticas diversas también es común en las tres revistas analizadas. El equipo de redacción de las tres publicaciones mantiene un compromiso con la calidad periodística al realizar un tratamiento de la información basado en la objetividad y en el contraste documental, aunque sigua encasillando a la lectora en los mismos universos temáticos de siempre.

Finalmente, el uso de tecnicismos también es crucial para comprender cómo la revista selecciona, procesa y muestra la información. Mientras que Telva opta por una castellanización de los conceptos procedentes de otras lenguas como inglés o francés, Elle y Vogue muestran un uso continuado de tecnicismos y anglicismos sin los cuales no podría entenderse o difícilmente podría entenderse la información de moda. Esta práctica tiene una posible explicación y es que, a diferencia de Elle y Vogue, Telva es una publicación de origen español que enfatiza valores tradicionales asociados a la moral, la familia y la unidad familiar frente a otro tipo de contenidos.

Por lo tanto, la segunda hipótesis de partida se ha cumplido al afirmar que las revistas analizadas realizan un completo ejercicio de calidad periodística al garantizar el contraste de fuentes y el uso de tecnicismos.

En conclusión, las revistas femeninas analizadas aún siendo dirigidas por mujeres no realizan desde las páginas un ejercicio basado en el feminismo, es decir, en la igualdad social, laboral y funcional entre hombres y mujeres, sino que resaltan los mismos roles establecidos en la sociedad desde tiempos inmemoriales para los hombres y las mujeres. Es necesario por lo tanto una profunda transformación que ayude a generar la visibilidad que requieren las mujeres en una sociedad eminentemente masculina, donde la mitad de la población son mujeres con una voz y una presencia invisible más allá de las noticias de moda, los productos para adelgazar o los últimos trucos para deshacerse de la celulitis.

\section{Referencias Bibliográficas}

BARREDO, D. (2015): “Big Data y técnicas cuantitativas: una introducción al análisis de contenido informatizado" en Revista San Gregorio. Ecuador, número 8 (2), pp. 106-111.

BERELSON, B. (1952): Content analysis in Communication Researches, Glencoe: Free Press. 
BONVOISIN, S. y MAIGNIEN, M. (1986): La presse féminine, París: Presses Universitaires de France.

BORDAS, J. (2015): Técnicas de investigación social aplicadas al análisis de los problemas sociales, Madrid: Universidad Nacional a Distancia (UNED).

CABELLO, F. (1999): El mercado de las revistas en España. Concentración informativa. Barcelona: Ariel.

CORBETTA, P. (2003): Metodología y técnicas de investigación social, Madrid: McGrawHill.

DE SOUSA, F. (2007): Introducción a la historia de la indumentaria en España, Madrid, Ediciones Istmo, S.A.

EGUIZABAL, R. (2008): Moda, comunicación y sociedad, Sevilla, Comunicación Social.

FIGUERAS, J. (2012): Historia de la Moda: Pasado, Presente y Futuro, Madrid, Eiunsa. Ediciones Internacionales Universitarias, S.A.

GALLEGO, J. (1990): Mujeres de papel. De iHola! A Vogue: La prensa femenina en la actualidad, Madrid, Icaria.

GANZÁBAL, M. (2006): “Nacimiento, evolución y crisis de la prensa femenina contemporánea en España" en Ámbitos Revista Internacional de la Comunicación, número 015, pgs. 405-420.

JIMÉNEZ, I. (1992): La prensa femenina en España: (desde sus orígenes a 1868), Madrid Ediciones de la Torre.

KRIPPENDORF, K. (1990): Metodología de análisis de contenido. Teoría y práctica. Barcelona: Paidós Ediciones.

LIPOVETSKY, G. (1990): El imperio de lo efímero: La moda y su destino en las sociedades modernas, Barcelona, Anagrama.

- (2002): La tercera mujer: permanencia y revolución de lo femenino, Barcelona, Anagrama.

LUQUE ORTIZ, S. (2017): La relación existente entre la sociología del consumo y el mensaje periodístico especializado de las revistas de moda. Un caso práctico: Telva, Elle España y Vogue España. Tesis doctoral, Universidad de Sevilla.

MATTELART, M. (1982): Mujeres e industrias culturales. Barcelona: Anagrama.

PENA, P. (2001): “Análisis semiológico de la revista de modas romántica" en Estudios sobre el Mensaje Periodístico, núm. 7, pp. 365-381. 
PÉREZ, C. y LUQUE, S. (2015): "La infoxicación de los grupos de poder en las publicaciones de moda. Análisis de calidad de contenidos en las revistas especializadas de moda: De Vogue América a Telva España" en Ámbitos, núm. 34, pgs. 91-101

PERRINAT, A. y MARRADES, M.I. (1980): Mujer, prensa y sociedad en España: 18801939. Madrid: Centro de Investigaciones Sociológicas.

PLAZA, J. (2005): Modelos de varón y mujer en las revistas femeninas para adolescentes. La representación de los famosos. Madrid: Editorial Fundamentos.

PIÑUEL, J.L. (2002): “Epistemología, metodología y técnicas del análisis de contenido" en Estudios de Sociolinguística. Lingua, sociedades e culturas. Universidad de Vigo, número 3 (1) pgs. 1-42.

POPPING, R. (2000): Computer-assisted text analysis. London: Sage.

SANTA CRUZ, A. y ERAZO, V. (1980): Compropolitan. El orden transnacional y su modelo. Madrid: Nueva Imagen.

SCHRÖEDER, H. (1981): Mulher de papel: a representaçao da mulher na imprensa feminine brasileira. Río de Janeiro: Ediçoes Loyola.

TIMOTEO, J. (1997): Del viejo orden informativo. Introducción a la historia de la comunicación, la información y la propaganda en Occidente, desde sus orígenes hasta 1880. Madrid: Actas.

WIMMER, R. y DOMINICK, J. (1996): La investigación científica de los medios de comunicación: Una introducción a sus métodos. Barcelona, Bosch.

WHITEHORNE, O. (1997): Cosmo Woman: The world of women's magazines. United Kingdom. Kent Crescent Moon Publishing. 